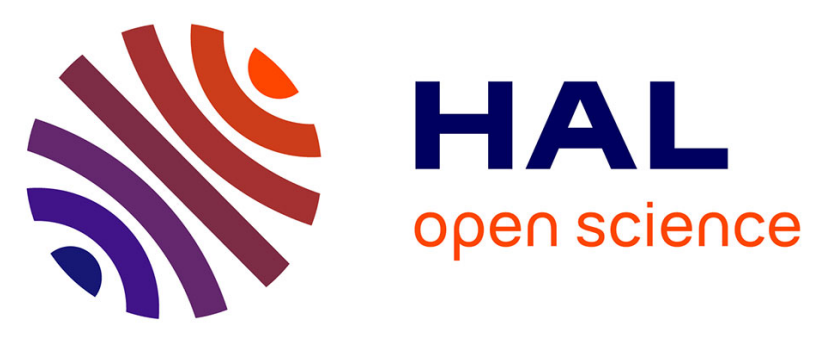

\title{
Road density and forest fragmentation shape bat communities in temperate mosaic landscapes
}

Alexis Laforge, Luc Barbaro, Yves Bas, François Calatayud, Sylvie Ladet, Clélia Sirami, Frédéric Archaux

\section{To cite this version:}

Alexis Laforge, Luc Barbaro, Yves Bas, François Calatayud, Sylvie Ladet, et al.. Road density and forest fragmentation shape bat communities in temperate mosaic landscapes. Landscape and Urban Planning, 2022, 221, 10.1016/j.landurbplan.2022.104353 . hal-03540699

\section{HAL Id: hal-03540699 \\ https://hal.inrae.fr/hal-03540699}

Submitted on 24 Jan 2022

HAL is a multi-disciplinary open access archive for the deposit and dissemination of scientific research documents, whether they are published or not. The documents may come from teaching and research institutions in France or abroad, or from public or private research centers.
L'archive ouverte pluridisciplinaire HAL, est destinée au dépôt et à la diffusion de documents scientifiques de niveau recherche, publiés ou non, émanant des établissements d'enseignement et de recherche français ou étrangers, des laboratoires publics ou privés.

\section{(1) (1) $\$$}

Distributed under a Creative Commons Attribution - NonCommercial - NoDerivatives| 4.0 
Research Paper

\title{
Road density and forest fragmentation shape bat communities in temperate mosaic landscapes
}

\author{
Alexis Laforge $^{\mathrm{a}, \mathrm{b}, \mathrm{c}}$, Luc Barbaro ${ }^{\mathrm{b}, \mathrm{c}}$, Yves Bas ${ }^{\mathrm{c}, \mathrm{d}}$, François Calatayud ${ }^{\mathrm{b}}$, Sylvie Ladet ${ }^{\mathrm{b}}$, \\ Clélia Sirami ${ }^{\mathrm{b}}$, Frédéric Archaux ${ }^{\mathrm{e}, *}$ \\ ${ }^{a}$ Conservatoire d'Espaces Naturels Midi-Pyrenees, 75 voie du TOEC, BP 57611, 31076 Toulouse, France \\ ${ }^{\mathrm{b}}$ Université de Toulouse, INRAE, UMR DYNAFOR, Castanet-Tolosan, France \\ ${ }^{\mathrm{c}}$ Centre d'Ecologie et des Sciences de la Conservation (CESCO), Museum national d'Histoire naturelle, CNRS, Sorbonne Université, Paris, France \\ ${ }^{\mathrm{d}}$ CNRS, Université de Montpellier, Université Paul Valery Montpellier 3, EPHE, IRD, Montpellier SupAgro, INRAE, UMR 5175 CEFE, F-34293 Montpellier, France \\ ${ }^{\mathrm{e}}$ INRAE, UR EFNO, Domaine des Barres, 45290 Nogent-sur-Vernisson, France
}

\section{H I G H L I G H T S}

- Bat diversity peaked in landscapes with intermediate forest fragmentation levels.

- Road density had negative effects on functional and phylogenetic bat diversity.

- Road density impacted bat activity differently between forest edges and interiors.

- Forest fragmentation mediated road density effects on bats at landscape scale.

- Our study advocates for more holistic approaches in fragmentation studies.

\section{A R T I C L E I N F O}

\section{Keywords:}

Chiroptera

Edge effects

Habitat fragmentation

Matrix quality

Multidimensional diversity

Road network

\begin{abstract}
A B S T R A C T
Road construction is expanding worldwide, exacerbating both direct mortality by road-kills and habitat fragmentation, especially for mobile vertebrates such as bats. Understanding how road density affects bat communities in mosaic landscapes of various compositions and configurations is therefore critical. We acoustically sampled bat communities in 172 landscapes of southern France to: (i) disentangle the relative and interacting effects of road density and forest fragmentation by farmland on the activity of bat communities; (ii) investigate how road density affects different aspects of bat diversity (taxonomic, functional and phylogenetic) and species activity according to their life-history traits; and (iii) assess whether road density effects on bats change with the level of forest fragmentation. Forest amount and patchiness were more important than road density for all components of bat diversity, except for functional evenness. Bat diversity peaked in landscapes with intermediate levels of forest fragmentation, while road density had negative effects on functional and phylogenetic diversity. The effect of road density on the activity of $R$. ferrumequinum, $R$. hipposideros, $N$. leisleri and P. pipistrellus was only negative in landscapes with either a low forest amount or a low number of forest patches. By better understanding interactions between forest fragmentation and road density, our study will contribute to a more adequate landscape planning that will improve the resilience of bat communities to both road expansion and forest fragmentation. Moreover, the complex landscape-level interactions between habitat fragmentation and matrix quality on bats advocate for the use of a more holistic view in future fragmentation studies.
\end{abstract}

\section{Introduction}

Habitat fragmentation at the landscape level is a major ongoing process in temperate landscapes, leading animals - and especially mobile vertebrates - to deeply change their movements and habitat use (Pfeifer et al., 2017; Tucker et al., 2018). The process of habitat fragmentation primarily may refer to a reduction in habitat amount leading to an altered spatial configuration and reduced connectivity (Carr et al.,

\footnotetext{
* Corresponding author.

E-mail address: frederic.archaux@inrae.fr (F. Archaux).
} 
2002), although its definition may also be restricted to fragmentation per se, i.e. to changes in habitat configuration without changes in habitat amount (Fahrig, 2017). However, both definitions agree in considering fragmentation as multifactorial and leading to both positive and negative responses of vertebrates to several underlying mechanisms including enhanced or reduced functional connectivity, positive or negative edge effects, changes in matrix quality or habitat diversity, and increases or decreases in the magnitude of biotic interactions such as predation, parasitism or competition (Fahrig, 2017; Pfeifer et al., 2017; Fahrig, 2019). Among the factors strongly interacting with habitat fragmentation in temperate landscapes, road density is key, through its potential large-scale effects on population persistence (Carr et al., 2002; Fahrig \& Rytwinski, 2009).

Road networks have expanded by 12 million $\mathrm{km}$ worldwide since 2000 , and 25 million $\mathrm{km}$ of additional roads are expected by 2050 (Laurance et al., 2014). Road expansion is a complex phenomenon with cumulative negative impacts on bats beyond habitat fragmentation, including a barrier effect (Claireau et al., 2019), mortality due to collisions with vehicles (Medinas et al., 2021), and light and noise pollution, which disturb bats while commuting and foraging (Bennett \& Zurcher, 2013; Stone et al., 2015). In light of the rapid increase in road infrastructure, we need a better understanding of how road density affects bat communities compared to habitat fragmentation by other land use changes. In particular, we lack studies that would allow to better assess the relative importance of road effects at the landscape level, especially given that researchers often underestimate the effects of direct road-kills compared to habitat mitigation (Zimmermann Teixeira et al., 2017; Medinas et al., 2021). While no studies to date have specifically focused on estimating the relative effects of road density and habitat fragmentation on temperate forest bats, a previous study found both negative and positive effects of roads on forest insectivorous birds (Khamcha et al., 2018). Although temperate forests are key roosting and foraging habitats for bats, the relative effects of forest amount and configuration on bats at the landscape level have been studied mostly in tropical zones (Presley et al., 2019). Overall, forest amount in a landscape is generally considered as a more important predictor of bat diversity and activity than forest configuration (Ethier \& Fahrig, 2011; Arroyo-Rodríguez et al., 2016). Previous studies also found that landscapes with moderately fragmented forests often host the highest functional diversity, species richness or abundance in bats (Klingbeil \& Willig, 2009; Fuentes-Montemayor et al., 2013).

The relative importance of forest amount and configuration actually depends on bat life-history traits. For instance, forest amount plays a greater role for frugivorous bat species, while configuration has a higher impact on animal-eating bat species (Klingbeil \& Willig, 2009). Bat species with low mobility are more affected by configuration, whereas for more mobile species, the amount of a given habitat in a landscape generally outweighs the pure configuration effect (Fuentes-Montemayor et al., 2017). However, these effects on bat diversity and abundance vary greatly between studies and bioclimatic regions, found to be either positive, negative or both (Gorresen \& Willig, 2004; Ethier \& Fahrig, 2011). Furthermore, responses of bat species to forest fragmentation depend on landscape contexts, species traits and the spatial scale considered (Klingbeil \& Willig, 2009; Fuentes-Montemayor et al., 2017).

Recent reviews argued that a more holistic perspective is needed in fragmentation studies to elucidate the potential complex and intertwined relations between matrix quality and habitat fragmentation, and ultimately to better orientate future conservation efforts in landscape planning (Fahrig, 2017; Presley et al., 2019). Studies aiming to assess the effect of road density alongside habitat fragmentation therefore need to ensure that the effect of changes in matrix quality associated with different amount of roads will not be interpreted as an effect of habitat fragmentation (Fahrig, 2017). Here, we investigated both the effects of matrix quality, including road density, and landscape-level forest fragmentation on bat communities, particularly focusing on the potential role of the former in mediating responses to the latter. To better predict how habitat fragmentation may affect bat communities, we investigated different dimensions of bat diversity, including its functional and phylogenetic components (Cisneros et al., 2015). While taxonomic diversity measures the number of species, functional diversity summarizes the variability in life-history traits among species and therefore provides a mechanistic link to ecosystem resistance, resilience and functioning (Petchey \& Gaston, 2006). Phylogenetic diversity represents the longterm evolutionary potential of a community in response to current and future landscape modifications (Cisneros et al., 2015).

In the present work, we specifically aimed at: (i) disentangling the relative and interacting effects of road density and forest fragmentation (i.e. amount and patchiness) by farmland on the activity of bat communities; (ii) investigating how road density affects different aspects of bat diversity (taxonomic, functional and phylogenetic) and species activity according to their life-history traits; and (iii) assessing whether road density effects on bats change with the level of forest fragmentation.

\section{Materials and methods}

\subsection{Study area}

The study was carried out in the region of Occitanie, in southwestern France, in an area spanning $19583 \mathrm{~km}^{2}$ (N 43.70, E 1.56) (Fig. 1). The region has a predominantly temperate climate, lying at the intersection of the Atlantic, Mediterranean and Continental climatic zones, with the additional influence of the Pyrenees Mountains to the south (Fig. 1). The study area is below $400 \mathrm{~m}$ a.s.l. and is dominated by agriculture (crops, vineyards, pastures), with patches of grasslands and forests of various sizes (mainly mixed woods and deciduous stands), tree-lined hedgerows, rivers, and a large network of both major and minor roads (Fig. 1). The area hosts relatively high bat diversity, with a total of 27 bat species (Bodin et al., 2011). The study was conducted between June and October 2017, with a mean air temperature of $20.8{ }^{\circ} \mathrm{C}$ (oscillating between $38.3{ }^{\circ} \mathrm{C}$ in June and $1.5{ }^{\circ} \mathrm{C}$ in October) and average monthly precipitation of $38.6 \mathrm{~mm}$ (varying between $55.2 \mathrm{~mm}$ in July and 11.6 $\mathrm{mm}$ in October).

\subsection{Landscape and site selection}

We selected landscapes along a gradient of road density and forest amount in three sub-regions: the Lot $\left(5217 \mathrm{~km}^{2}\right)$, Tarn and Tarn-etGaronne $\left(9476 \mathrm{~km}^{2}\right.$ ) and Ariege districts $\left(4890 \mathrm{~km}^{2}\right.$ ) (Fig. 1). We excluded landscapes with elevations above $1000 \mathrm{~m}$ to keep climatic conditions comparable and to limit biases due to complex impacts of elevation on bat activity and richness (McCain, 2006). Within each subregion, we defined selected 'landscapes' with a square area of $1 \mathrm{~km} \times 1$ $\mathrm{km}$ (this scale was used only for selecting landscapes). To limit the effect of possible confounding variables, we excluded landscapes with $>20 \%$ of impervious surfaces (buildings and parking lots) and/or wetlands (lakes, ponds and watercourses). We calculated the amount of forest and road density in each $1-\mathrm{km}^{2}$ landscape and categorized them according to 8 classes (forest amount in \%: 0-12.5, 12.5-25, 25-37.5, 37.5-50, $50-62.5,62.5-75,75-87.5,87.5-100$; road density in $\mathrm{km} / \mathrm{km}^{2}$ : $0-5.5,5.5-11,11-16.5,16.5-22,22-27.5,27.5-33$, 33-38.5, 38.5-44). We chose this number of classes in order to cover the whole gradient and combination of variables. This resulted in 64 potential combinations of road density and forest amount for which we selected three replicates, one in each sub-region. As a few combinations were not represented in some sub-regions, the final set included 172 landscapes (Fig. 1). All landscape variables were calculated with ArcGis 10 (ESRI, Redlands, CA) based on land cover data obtained from the French Theia Land Data Centre (land use land cover layer OSO based on 2016 data used to quantify forest configuration and amount, (Inglada et al., 2017) and the French National Institute for Geographic and Forestry Information 


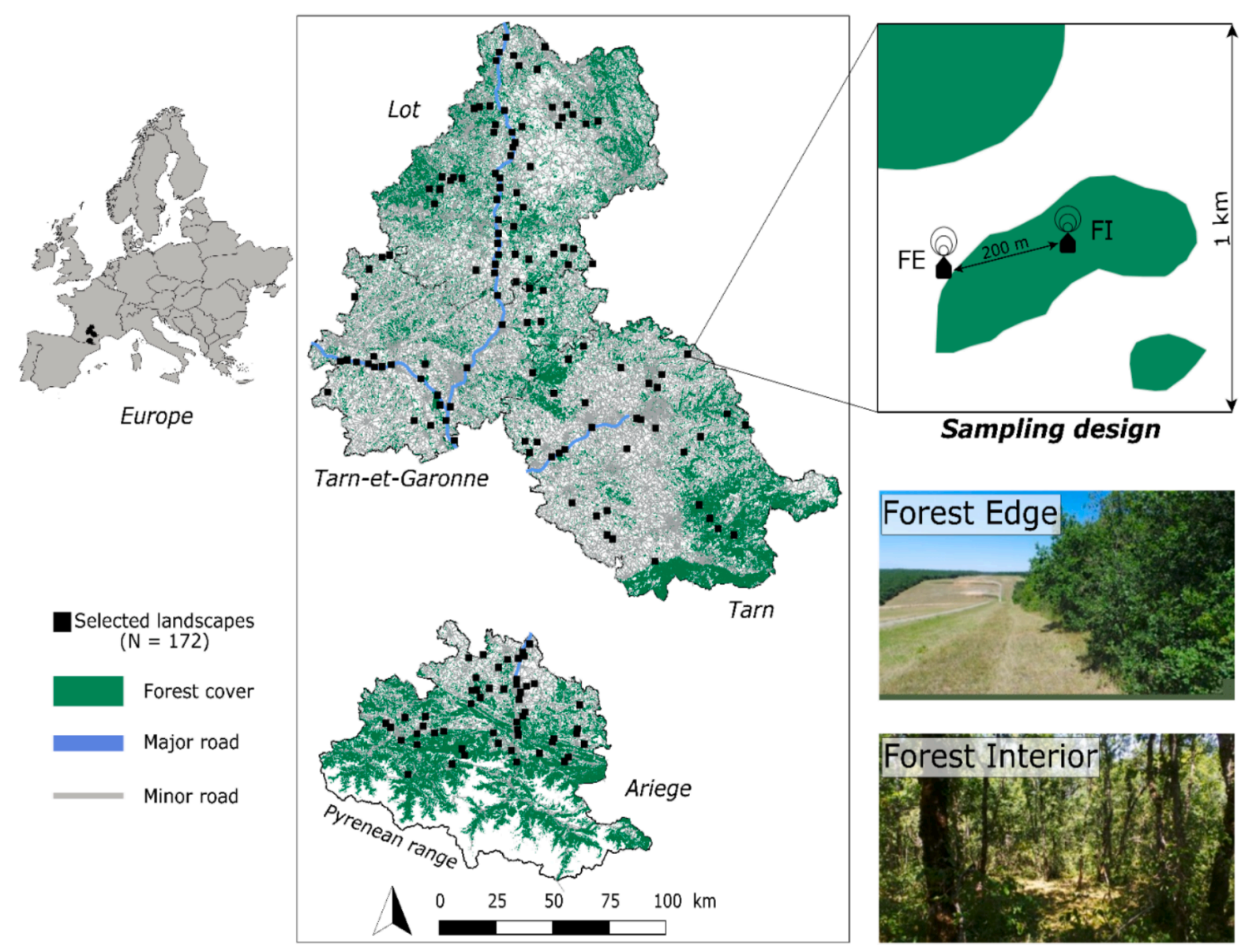

Fig. 1. Land cover map and location of selected landscapes in the study area, showing sampling design with simultaneous recordings of bat activity over one night at the forest edge and interior within each landscape.

(www.ign.fr/; BD TOPO๑ layer released in March 2017 used to quantify road density).

Forest patchiness (i.e., number of forest patches as a proxy of habitat configuration) was not fully independent from forest amount (i.e., forest proportion as a proxy of habitat amount) in our sampling design (see Appendix A), because we focused instead on orthogonal gradients of forest amount and road density at the landscape scale. Although forest amount and patchiness (the two components of fragmentation) were not highly correlated among our landscape levels ( $r<0.7$ and VIF $<4$ ), forest proportion and the number of forest patches revealed a typical hump-shaped relationship at 0.5 and $1 \mathrm{~km}$ scale but a strict positive relationship at the largest scales (i.e. 2, 3, 4 and $5 \mathrm{~km}$ radius). This means that our study did not include the less common combinations of low forest amount with high number of forest patches and high forest amount with low number of forest patches, being naturally the rarest landscape contexts because of intertwined patterns of forest amount and patchiness (Smith et al., 2009).

\subsection{Bat community sampling}

Within each of the 172 landscapes, we selected the forest patch closest to the landscape centroid for bat sampling (patch size (ha): mean $=600.7 ; \mathrm{SD}=2813.3 ; \min =0.1 ; \max =25629.7$ ). We deployed two automatic bat ultrasound recorders (Batlogger A, Elekon AG, Lucerne, Switzerland), one in the centre of the forest patch (i.e. forest interior) and the second at the interface between the forest and the semi-natural agricultural matrix (i.e. forest edge; Fig. 1), resulting in 344 recording points. The recorders were at least $200 \mathrm{~m}$ away from each other (mean distance: $412.3 \pm 183.8 \mathrm{~m}$ ) to avoid simultaneous recordings of the same bat calls. Microphones were placed $1.50 \mathrm{~m}$ above the ground and oriented upwards on a vertical axis. Each recorder was calibrated to be automatically triggered by any sound with a signal-to-noise ratio above $6 \mathrm{~dB}$ and to start recording ultrasound calls from half an hour before sunset to half an hour after sunrise.

Each landscape was surveyed twice, at two key periods in the annual bat life-cycle: parturition (sampled between 19 June and 27 July) and the dispersion and mating period (sampled between 23 August and 14 October), resulting in 675 full nights of recording (13 failed). We simultaneously surveyed eight landscapes at a time (16 deployed detectors) during one full night. The order in which we surveyed landscapes was chosen to limit correlations between landscape variables (forest amount and road density) and the date. Surveys were conducted only when there was no rain, the wind speed was below $30 \mathrm{~km} / \mathrm{h}$, and the ambient temperature was above $12{ }^{\circ} \mathrm{C}$.

\subsection{Bat call identification and response variables}

As it is currently impossible to determine the actual number of individual bats using acoustic data from passive ultrasound recorders, we calculated bat activity as the number of bat passes per night and per species. A bat pass was defined as one or several echolocation calls during a given 5-second interval. This time interval is considered to be the best trade-off to optimize bat pass duration among species with different call lengths and frequencies (Millon et al., 2015). In a first step, echolocation calls were detected and classified to the most accurate taxonomic level, allowing a confidence index to be assigned to each bat pass using the software Tadarida (Bas et al., 2017). The raw data was then divided into two subsets using two confidence index thresholds (see 
Appendix B - Table B1), corresponding to a predicted maximum error risk of 0.5 (a $0-50 \%$ probability of misidentifying a bat pass) or 0.1 (a $0-10 \%$ probability). The 0.5 confidence index threshold represented the best trade-off to retain a good quantity of data (in terms of number of bat passes and species occurrences), while the 0.1 threshold limited the number of false positives. To ensure robustness, we performed analyses on these two subsets to verify the consistency of the results (Barré et al., 2019). We conducted analyses at the species level for Pipistrellus pipistrellus, P. kuhlii, Barbastella barbastellus, Myotis crypticus, Rhinolophus ferrumequinum, $R$. hipposideros, Nyctalus leisleri and N. noctula, which all produce very distinctive calls (Obrist et al., 2004). We assigned all automatic identifications of Myotis nattereri to M. crypticus, which has recently been split genetically and geographically from the $M$. nattereri species complex, as our study area is within the range of this newly described species (Juste et al., 2018).

From our acoustic data, we measured four diversity indices: species richness, functional dispersion, functional evenness and phylogenetic diversity. Species richness (i.e. taxonomic diversity) considers species as distinct and is insensitive to ecological and evolutionary attributes. Functional dispersion measures the mean abundance-weighted distance of an individual species to the centroid of the more abundant species in a multidimensional trait space (Laliberté \& Legendre, 2010). Functional evenness measures the regularity of the distribution of species abundance and dissimilarities in the functional space; it represents the proportion of dominant species in the community, ranging between 1 , when the community is perfectly even, to 0 , when the community is dominated by one species (Villéger et al., 2008). These functional indices are complementary (respectively measuring dispersion and regularity in trait space) yet independent, representing two different facets of functional diversity (Laliberté \& Legendre, 2010). Lastly, we calculated the mean nearest taxon distance (MNTD), a phylogenetic diversity index that indicates the mean distance between each species in the phylogeny and its most closely related species in the sampled community (Vamosi et al., 2009). The MNTD measures the evolutionary difference between species based on the time since the divergence from a common ancestor (Faith, 1992). We calculated FDis and FEve using the dbFD function in R (R package 'FD'; (Laliberté \& Legendre, 2010), based on a dataset of 11 traits that we are confident to influence bat responses to forest fragmentation and road density (Santos et al., 2016; see Appendix B - Table B2). We computed MNTD using a tree-based method implemented in the ses.mntd function (R package 'Picante') and a phylogenetic tree obtained from https: //www.treebase.org/ (Tree ID $=$ Tr87680). Finally, we integrated species abundance variations in the phylogenetic and functional diversity calculations to better reflect finer variations in community structure and composition (Devictor et al., 2010).

\subsection{Calculation of local and landscape-level variables}

Within each landscape, we calculated road density, the proportion of forest, the number of forest patches, the Euclidean distance to the nearest paved road (whatever its width) and the Shannon diversity index calculated from all types of land cover (except forest habitat; $n=8$, i.e. cropland, grassland, orchard, pasture, road, urban, vineyard and waterbody) in the landscape matrix (see Appendix C - Fig. C1) using updated land use land cover data (OSO 2017, Inglada et al., 2017). As different bat species respond to the landscape at different spatial scales, we quantified landscape variables at six spatial scales (a radius of $0.5,1$, 2, 3, 4 and $5 \mathrm{~km}$ from each landscape centroid) to identify the strongest biologically relevant 'scale of effect' (Jackson \& Fahrig, 2012). The mean spatial overlap of our landscapes for each scale was $1 \%$ for $0.5 \mathrm{~km}$, $3 \%$ for $1 \mathrm{~km}, 11.2 \%$ for $2 \mathrm{~km}, 23 \%$ for $3 \mathrm{~km}, 34.4 \%$ for $4 \mathrm{~km}$ and $44 \%$ for $5 \mathrm{~km}$. Overlapping landscapes do not themselves represent a violation of independence and thus are distinct from the concerns of pseudo-replication (Zuckerberg et al., 2020). Furthermore, both empirical results and simulations have demonstrated that overlapping landscapes do not necessarily induce more residual spatial autocorrelation (Zuckerberg et al., 2020).

To statistically control for local habitat quality effects known to influence bat activity (Langridge et al., 2019), we measured the width and the height of each forest edge as well as the proportion of space between understory and canopy levels relative to the total height (Andrieu et al., 2018). For forest interiors, we measured the basal area (using a relascope) and mean vegetation clutter (proportion in four vertical height bands: $0-2 \mathrm{~m}, 2-10 \mathrm{~m}, 10-20 \mathrm{~m}$ and $>20 \mathrm{~m}$; see Table C1) within a circular area plot measurement ( $25 \mathrm{~m}$ radius) centered on the bat recorder location. To avoid collinearity in model predictors, we used a principal component analysis (PCA) to aggregate into axes local edge (PCA1) and forest interior (PCA2) attributes as two new variables (details in Appendix C - Fig. C2).

\subsection{Statistical analysis}

To assess how road density, forest amount and patchiness influenced bat activity and diversity, we used generalized linear mixed models (GLMM, R package 'glmmTMB'). Models were fitted using a Gaussian distribution for the bat diversity variables (richness, FDis, FEve and MNTD) and a negative binomial error distribution for bat activity (the number of bat passes per night for each species) with a log link function to take into account overdispersion in our data. Potential non-linear effects of each landscape predictor were visually checked on biplots from generalized additive mixed models (GAMM, R package (mgcv').We detected non-linear relationships for richness, FDis, FEve and MNTD with forest amount, and for FDis and MNTD with the number of patches (Appendix D - Fig. D1). In those cases, we added a quadratic effect for these two predictors in the models. We included the first two PCA axes (the local predictors being potential confounding factors to be taken into account) and the five landscape covariates (Table C1; our factors of interest) as fixed effects in the full models, while 'landscape' and 'date' were included as random effects to account for the non-independency of our paired recording points (i.e. at both forest edge and interior) and for the same weather conditions between all landscapes sampled during a given night, respectively. The seven continuous fixed effects were scaled so that the associated regression coefficients were comparable in magnitude and their effects were biologically interpretable (Schielzeth, 2010). Forest amount and patchiness are not fully independent $(R=0.37,0.45,0.68,0.65,0.69$, 0.7 at $0.5,1,2,3,4$ and $5 \mathrm{~km}$ scales, respectively) but they were both included as predictors in the models because they can be seen as proxies of distinct ecological processes related to bat responses to fragmentation (Fahrig, 2017). Furthermore, Smith et al., (2009) found by simulations that if forest amount and number of forest patches are controlled for, even when highly correlated (i.e. as potential confounding predictors), then standardized partial regression coefficients are unbiased estimates. Because forest proportion and number of forest patches have a suppressor relationship in our study, i.e., opposite qualitative effects (see results) and a positive correlation (Appendix A), removing one would underestimate the effects of our remaining predictors and would decrease the explanatory power of our models. Furthermore, despite using an urban filter during landscape selection, the road network was still correlated (Spearman's correlation $>0.7$ ) with urban cover and average radiance (i.e. light pollution). Consequently, we carried out a complementary analysis to test whether urban cover or light pollution better explained the data compared to road density at the best scale for each response variable (Appendix D). We also checked the correlation between local forest variables (i.e. PCA axes) and landscape forest variables (Table C.2 in Appendix C). Considering both the low Pearson's R values $(<|0.28|$ for PCA1 and $<1$ 0.10 for PCA2) and the low VIF values associated with PCA1 and PCA2 in models (VIF $<1.31$ in Table D. 2 in Appendix D), we considered both local and landscape variables related to forests in our full models (see below). 
To take into account expected differences in bat activity and diversity between forest edges and interiors, we used a two-level factor related to the location of the bat recorder at each forest patch: forest interior (FI) versus forest edge (FE). To explore the potential interacting effects of road density and forest fragmentation by farmland on bat communities (objectives $\mathrm{i}$ and iii), we also included three interaction terms in the models, i.e. between edge/interior location and road density, between road density and forest amount, and between road density and forest patchiness. For each of our 12 response variables, six full single-scale models were built with all 11 predictors, as follows: significantly different responses to road density between forest edges and interiors (Fig. 4). The effect of road density was positive in forest interiors, but negative for $R$. ferrumequinum and neutral for $P$. pipistrellus at forest edges. For $P$. kuhlii, road density was positive at both forest locations, although this effect was stronger in forest interiors than at forest edges (Fig. 4). For $N$. noctula, activity increased with road density at forest edges, but decreased in interiors. For phylogenetic diversity, we found that road density had no effect at forest edges, but had a negative effect in interiors (Fig. 4). The effect of road density on bats also depended on forest fragmentation (amount and patchiness; Fig. 5). A

Bat Activity or Diversity $\sim$ PCA1 + PCA2 + Road_dens + Forest_prop + Numb_forestp + Dist_road + Matrix_div + FI $/ F E+F I / F E$

$:$ Road_dens + Road_dens $:$ Forest_prop + Road_dens $:$ Number_forestp $+1 \mid$ Date $+1 \mid$ Landscap

We calculated multivariate regressions (R-package 'MuMIn') for all possible combinations of predictor variables and performed AICc-based model averaging using only the best models within $\Delta$ AICc $\leq 2$. Model averaging calculates the averaged coefficients and relative variable importance (RVI) for each predictor as the sum of AICc weights of all top models containing that variable (Burnham \& Anderson, 2002). This procedure was conducted at all six spatial scales for each response variable, and the best scale was defined by the highest $R^{2}$ among the six models (Appendix D - Table D1). We considered effects to be significant when RVI values were 0.6 or above (as Dencker et al., 2017). We checked for multicollinearity by conserving only variables with Spearman's correlation $<0.7$ and a VIF value $<4$ (Appendix D - Table D2). We checked for spatial autocorrelation in the residuals of the best models using the dnearneigh and sp.correlogram functions in R package 'spatial' and found no significant spatial autocorrelation. We did not detect any overdispersion in the best models (ratio $<1$ ) by visual examination of residual plots (Zuur et al., 2009). We performed all analyses in $\mathrm{R}$ version 3.3.1. (R Core Team, 2018).

\section{Results}

In total, 263463 passes of 21 bat species were recorded at the 675 recording points spread over 172 landscapes (Table B1). The best models from multi-model averaging showed model fits (conditional $R^{2}$ ) of $0.19-0.48$ for bat activity (with the highest variance for $P$. kuhlii) and of $0.07-0.29$ for bat diversity (with the highest variance for species richness; see Figs. 2 and 3 and Table D1). Overall, forest amount or its patchiness (i.e. the number of forest patches) were always more important than road density for bat diversity, except for functional evenness (Fig. 2). In contrast, at the species level, forest amount or its patchiness were more important than road density for only two of the eight studied species, while it was equally important for the six other species (Fig. 3). Results were similar for both confidence thresholds, so we only present outcomes for the 0.5 threshold of maximum error risk tolerance (Fig. 2).

\subsection{Effect of road density on bat communities}

Road density had a significant effect (RVI $>0.6$ ) on all bat species and diversity metrics, except for $B$. barbastellus, which responded more strongly to the distance to the nearest road (Figs. 2 and 3). The effect of road density was negative for functional and phylogenetic diversity and for the activity of M. crypticus and R. hipposideros, but positive for the activity of $N$. leisleri, $N$. noctula, $P$. kuhlii, $P$. pipistrellus and R. ferrumequinum (Figs. 2 and 3). For four of these five species, we found significant positive effect of road density on $P$. pipistrellus occurred only in landscapes with a high number of forest patches at the $0.5 \mathrm{~km}$ scale. For $R$. ferrumequinum and $R$. hipposideros, the negative effect of road density was significant only in landscapes with low, or both low and intermediate numbers of patches, respectively. Finally, road density had a significant negative impact on $N$. leisleri only in landscapes with a low amount of forest.

\subsection{Relative effects of forest amount and patchiness on bats}

For seven out of eight species, forest patchiness was more or equally important than forest amount, while the reverse was only true for $N$. noctula (Fig. 3). More precisely, a higher number of patches had a positive effect on the activity of five species, but a negative one on the two Pipistrellus species. In contrast, we did not find any positive effects of forest amount on bat activity. The effect of forest amount on functional diversity (FDis) was also negative, whereas species richness showed a hump-shaped response (quadratic term), with maximum taxonomic diversity in landscapes with $40-50 \%$ of forest cover (Fig. 6). The effect of forest patchiness on functional and phylogenetic diversity also showed a hump-shaped response, with a maximum occurring at an intermediate number of patches (Fig. 6). Moreover, we found that the activity of six species and two diversity metrics were significantly higher at forest edges compared to interiors, while no significant differences were found for $M$. crypticus, $N$. noctula nor phylogenetic diversity. In contrast, only functional evenness was significantly higher in forest interiors (Fig. 7). Finally, landscape matrix diversity was important (RVI $>0.6)$ for three species (N. noctula, $P$. kuhlii and R. ferrumequinum) and for phylogenetic diversity (MNTD), with both positive and negative effects (Figs. 2 and 3; see Appendix C - Fig. C1 for interpretation).

\section{Discussion}

Forest amount and patchiness were more important than road density for all bat diversity components but functional evenness. Bat diversity was highest in landscapes with intermediate levels of forest fragmentation, while functional and phylogenetic diversity decreased with increasing road density. This negative effect of road density on the activity of $R$. ferrumequinum, $R$. hipposideros, N. leisleri and P. pipistrellus was only found in landscapes with either a low forest amount or a low number of forest patches. While models explained a good proportion of data variance for species richness (conditional $\mathrm{R}^{2} 0.29$ ) and individual species (from 0.26 to 0.41 ), this proportion was noticeably lower for three other diversity metrics (between 0.7 and 0.11 ). As a result, detailed results reported below for taxonomic, functional and phylogenetic diversity should be carefully interpreted.

In our temperate study area, forest amount and patchiness (i.e. forest 


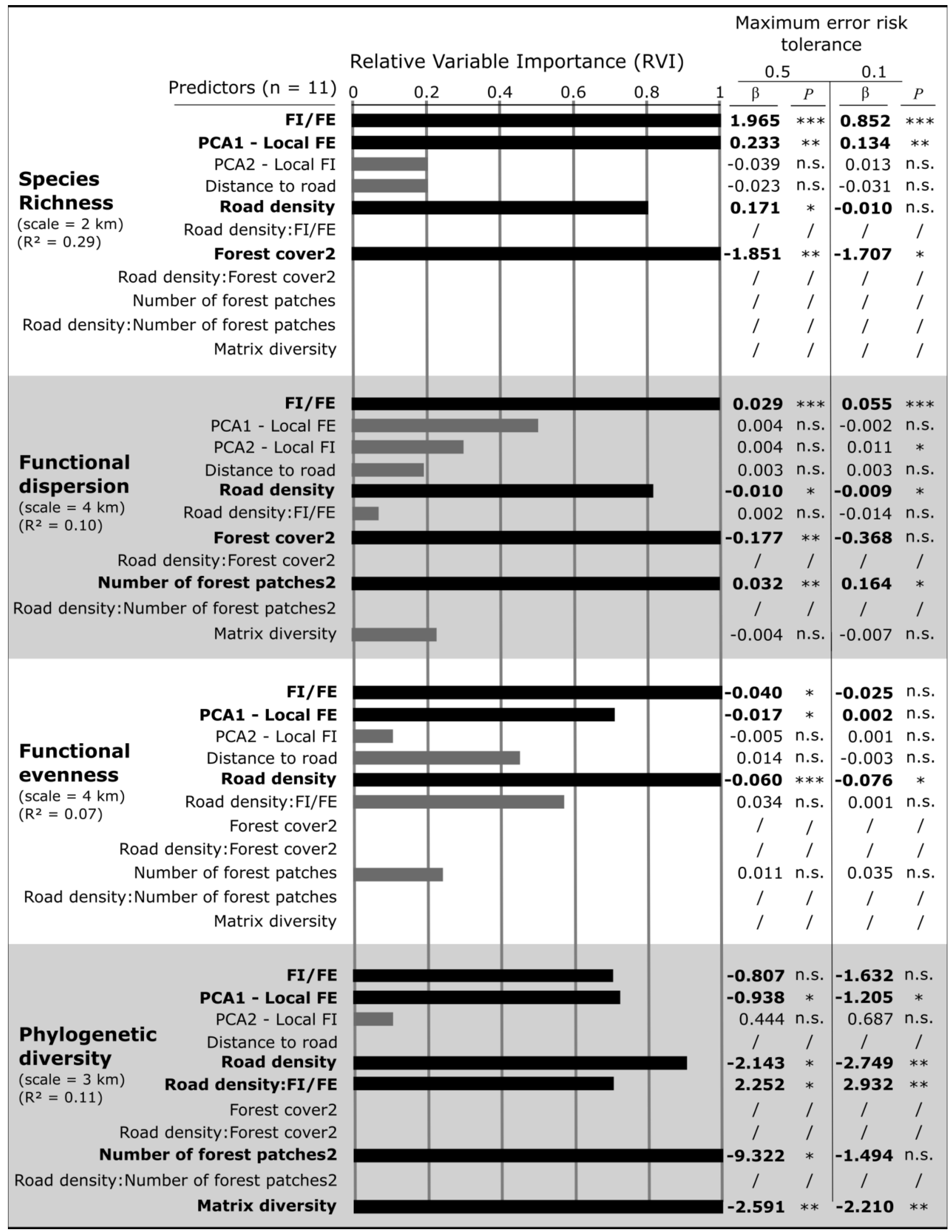

Fig. 2. Relative importance (bar length), estimates $(\beta)$ and significance $(* P<0.05 ; * * P<0.01 ; * * * P<0.001$; n.s. $=$ not significant) of model-averaged multiple regressions for the four bat diversity indices at their best scale (highest $\mathrm{R}^{2}$ of the best model). The relative importance of predictor variables indicates the individual contribution of the variable to the explanatory power of the models (a value of 1 indicates its presence in all top models; bar is black if $>0 \cdot 6$ ). $P$-values are only provided for comparison of the model averaging approach with null hypothesis testing. Forest interiors were used as the reference (i.e. intercept) in each model. A predictor followed by the number 2 indicates quadratic terms. 


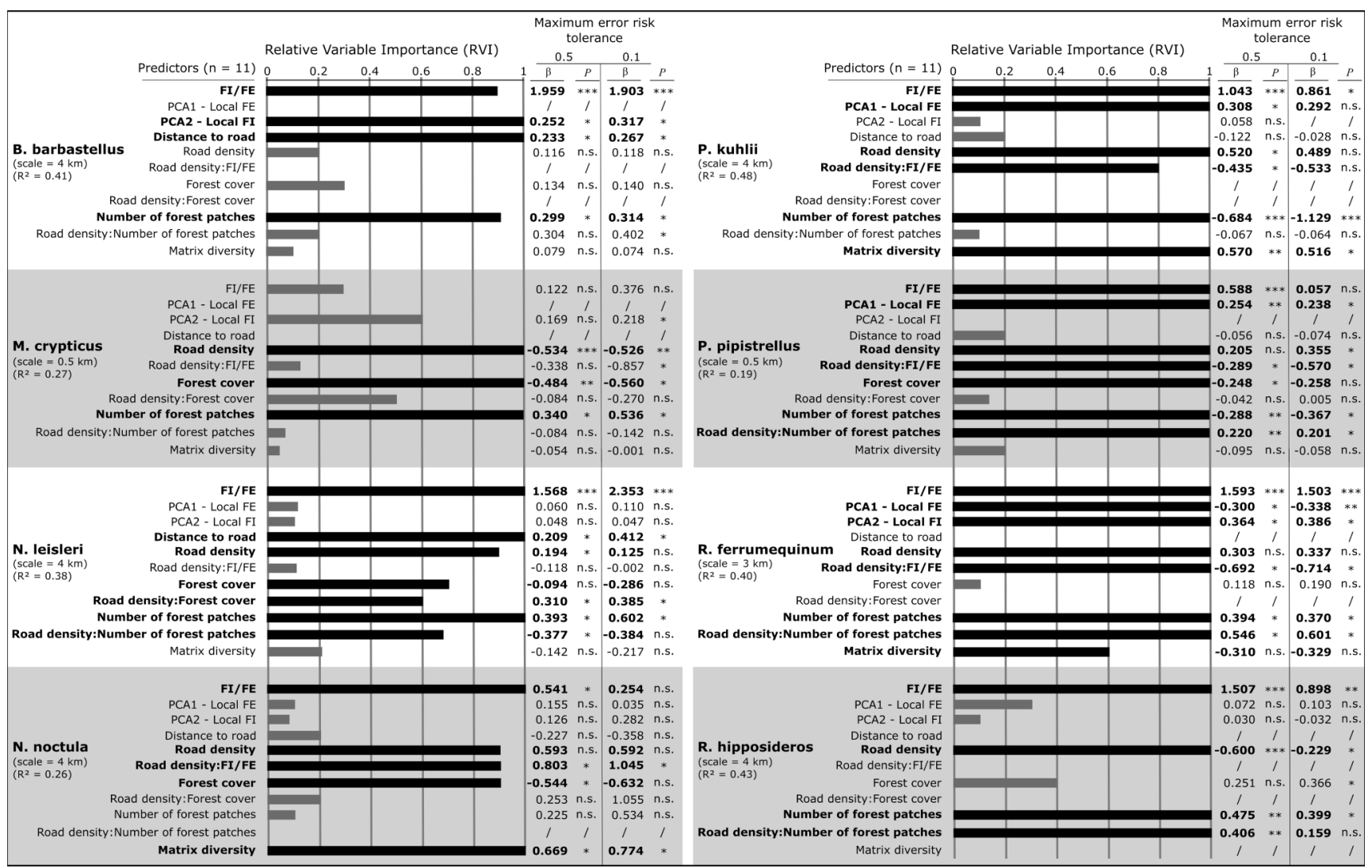

Fig. 3. Results from model-averaged multiple regressions for the activity of 8 bat species (i.e. number of bat passes per night). See details in caption of Fig. 2 .

fragmentation) were more important drivers for shaping bat communities than road density in regard to taxonomic, phylogenetic and functional diversity. Only functional evenness was more negatively affected by road density and edge effects than forest amount and patchiness. However, we found that most bat responses to road density were both species-specific and context dependent. Taxonomic diversity of bat communities was best explained by forest amount, while functional and phylogenetic diversity were best explained by a combination of forest amount and patchiness (i.e. number of patches). We found that bat species richness peaked at intermediate forest amounts, while functional and phylogenetic diversity peaked at intermediate levels of forest patchiness. This suggests that landscapes with forest habitat moderately fragmented (in terms of both amount and number of patches) mixed with other land uses would produce the best environmental conditions for maintaining the highest bat diversity (Bailey et al., 2019). At the landscape level, these environmental conditions may be optimal by providing sufficient resources for both foraging and roosting to the widest range of bat species and life-history traits (Klingbeil \& Willig, 2009).

Taxonomic, functional and phylogenetic diversity as well as the eight bat species responded to road density and forest fragmentation at multiple spatial scales (from 0.5 to $4 \mathrm{~km}$ radii; see Figs. 2 and 3). We note that our 'scales of effect' for both bat diversity and activity were not equal to the smallest or largest scale evaluated (except for two species), suggesting that our range of scales was relevant and that our diversity/ species-landscape relationships are estimated at the most biologically relevant scale (Jackson \& Fahrig, 2015). However, our 'scales of effect' for bats' activity were not consistent with species home range size (i.e. mobility; see Table B2) and previous studies (Boughey, Lake, Haysom, \& Dolman, 2011; Ducci et al., 2015; Fuentes-Montemayor, Goulson, Cavin,
Wallace, \& Park, 2013; Fuentes-Montemayor, Goulson, \& Park, 2011). Across-study comparisons of the 'scale of effect' is difficult since (i) the 'scale of effect' may simultaneously depend on multiple biological factors (e.g. dispersal distance, reproductive rate, population density); and (ii) the estimated 'scale of effect' for a given species or group may vary among studies depending on many methodological choices (e.g. landscape variables measurement, range of spatial scales considered, statistical approach and selection criteria used to identify the 'scale of effect') but also on the regions where the studies were carried out (Miguet et al., 2016).

\subsection{Effects of road density on three-dimensional bat diversity}

Beyond effects of forest fragmentation, the density of the road network had a significant negative influence on bat functional and phylogenetic diversity, but not on taxonomic diversity. We thus demonstrate that considering only taxonomic species richness may be limited for conservation purposes, as it could mask losses of key ecological or evolutionary attributes of bat assemblages, likely involving a decreased resilience to landscape modification due to road network densification (Cisneros et al., 2014). Moreover, positive or nonsignificant effects of roads on taxonomic diversity may be coupled with significant decreases in functional and phylogenetic diversity, which would suggest that roads act as environmental filters and could lead to a biotic homogenization of bat communities at the landscape level (Monnet et al., 2014). Lower variations in functional diversity, compared to other aspects of diversity, along environmental gradients have been actually documented in a variety of taxa, including tropical bats (Cisneros et al., 2014). Based on the life-history traits we used to calculate functional diversity indices, we could speculate that road 
Predicted bat activity variation at the:

forest edges (FE)

forest interiors (FI)

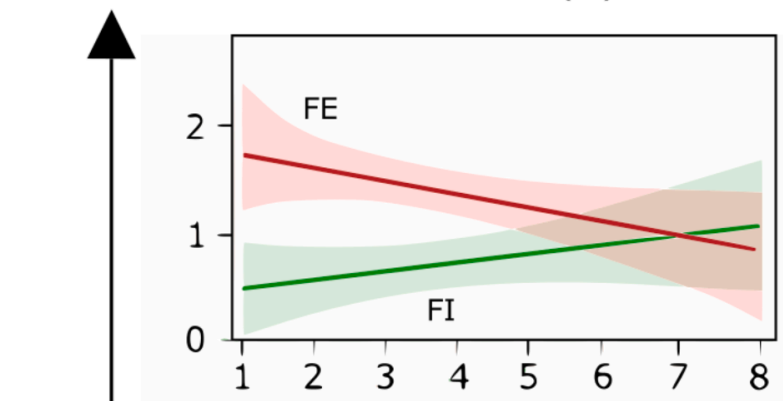

Rhinolophus ferrumequinum

$3 \mathrm{~km}$ scale

Pipistrellus

kuhlii

$4 \mathrm{~km}$ scale
Fig. 4. Predicted bat responses to road density at forest edges versus forest interiors from at the 'scale of effect'. Only selected interactions in the best models are presented (i.e. RVI >0.6; see Figs. $2 \& 3$ ). Values on the y-axis are the number of bat passes per night (i.e. activity). The red and green bands represent the $95 \%$ confidence interval for the predicted values at the forest edges and interiors respectively. (For interpretation of the references to colour in this figure legend, the reader is referred to the web version of this article.)

\section{Pipistrellus pipistrellus}

$0.5 \mathrm{~km}$ scale

\section{Nyctalus noctula}

$4 \mathrm{~km}$ scale
FI

0
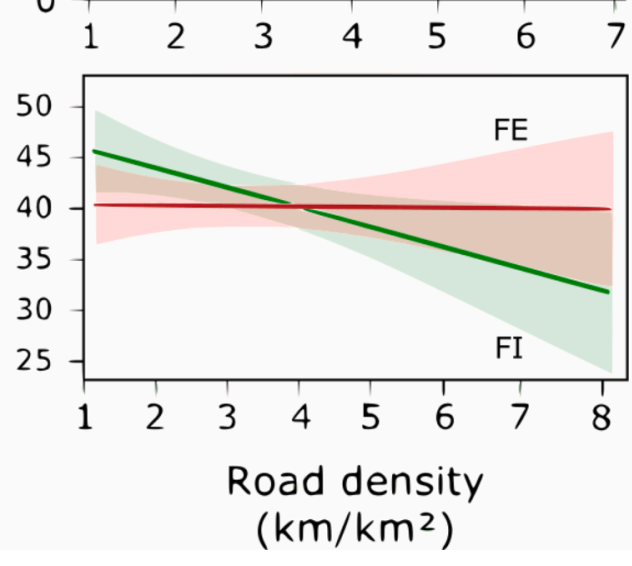

Phylogenetic diversity

$3 \mathrm{~km}$ scale 


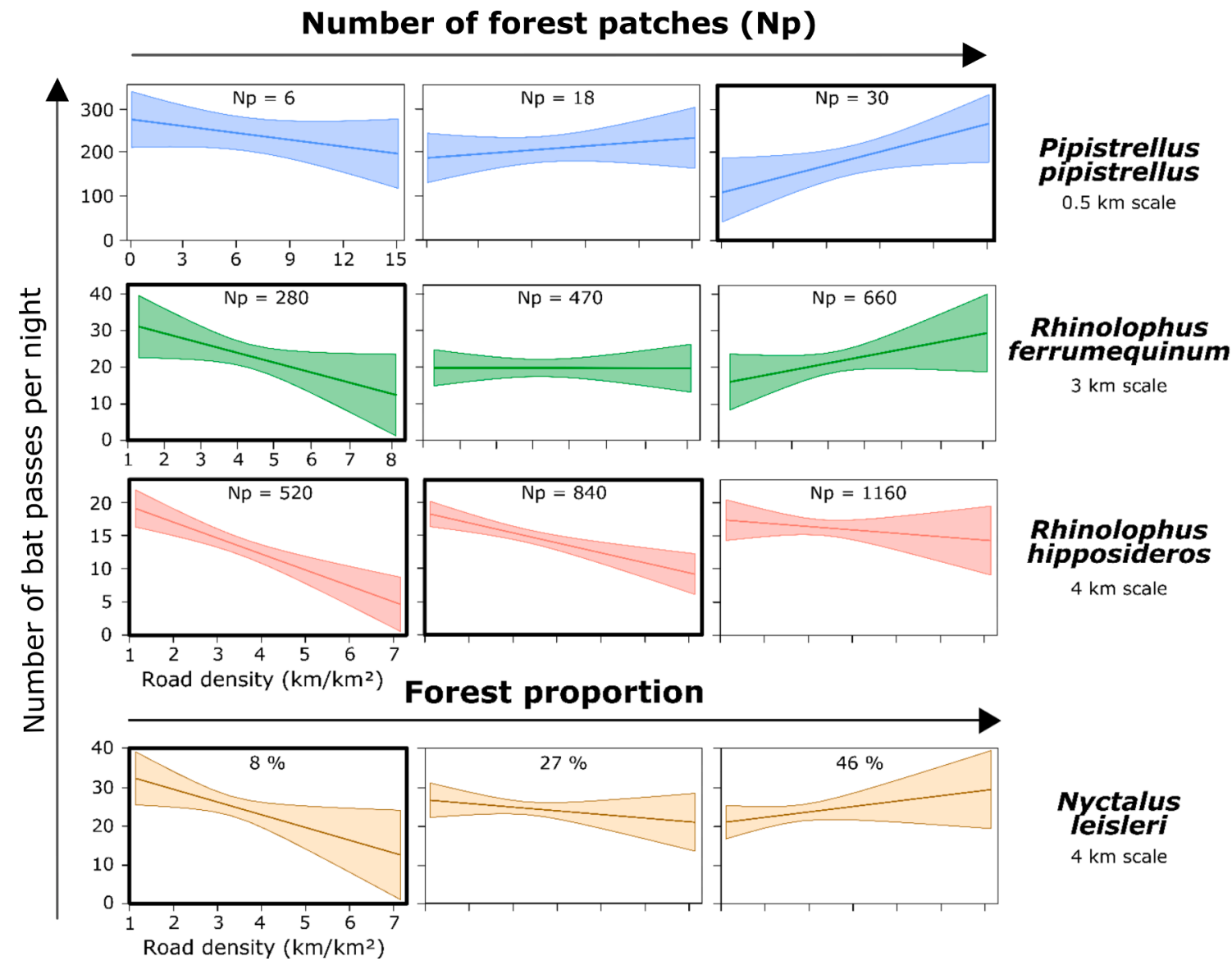

Fig. 5. Predicted bat responses to road density (with the $95 \%$ confidence interval) at three different levels of forest amount and patchiness at the 'scale of effect'. Only selected interactions in the best models are presented (i.e. RVI > 0.6; see Fig. 3). The three levels have been calculated according to the standard 'spotlight analysis' as follows: mean - SD; mean; mean + SD. Values on the y-axis are the number of bat passes per night (i.e. activity). Bold frames represent significant slopes (i.e. $95 \%$ confidence interval not containing zero).

density favours bat species flying at higher height because they are less vulnerable to the risk of road-kills and disturbance related to road traffic (Claireau et al., 2019; Medinas et al., 2019). Since the time spent at height is linked with acoustic performances and wing morphology among bats (Roemer et al., 2019), we could also speculate that (i) species with sonar adaptations for long-distance perception of their environment (i.e. low frequency signals, small bandwidths, and long call length) and (ii) species with high wing aspect ratio and loading (which is positively correlated to body mass; Norberg \& Rayner, 1987), should be able to better persist within landscapes with a denser road network. Several assembly mechanisms may differently influence the set of bat traits that we used to calculate functional diversity. For instance, a given mechanism could favour one trait and discriminate against another, leading to no change in functional diversity. An increase in functional and phylogenetic diversity could come either from adding more ecological or evolutionary attributes to a bat community, or from a decrease in abundant and/or a loss of redundant species, both of which would enhance the distribution, dispersion and/or regularity of traits in the functional space (Cisneros et al., 2014). Ultimately, changes in functional and phylogenetic diversity observed in our study may reflect a combination of mechanisms for which the species-specific responses, related to life-history traits, can provide further insights.

\subsection{Bat activity responses to road density according to life-history traits}

Road expansion has cumulative negative impacts on bats: habitat fragmentation (Carr et al., 2002), barrier effect (Claireau et al., 2019), collision with vehicles (Medinas et al., 2021) and diverse pollutions/ disruptions (Bennett \& Zurcher, 2013; Stone et al., 2015). Furthermore, roads generally develop together with overall urbanization and agriculture intensification and thus correlate with urban cover and light pollution, which is verified in our study. Road network density can be therefore viewed as a proxy of the overall matrix quality for bats, by indicating a global anthropization level of the landscapes (Fahrig, 2017). As expected, road density had a negative effect on the lowestflying species (M. crypticus) and on the most specialized species to forest interiors ( $R$. hipposideros). Those species are particularly vulnerable to road effects (Fensome \& Mathews, 2016) and anthropogenic pressures on temperate landscapes, known to be the main drivers in the decline of specialist bats at the expense of generalists (Russo \& Ancillotto, 2015). Road density had a positive effect on the highest-flying and most generalist species (Pipistrellus and Nyctalus spp.) and non-forest interior specialists ( $R$. ferrumequinum). More precisely, the activity of $R$. ferrumequinum, $P$. kuhlii and $P$. pipistrellus in forest interiors increased with road density, while it tended to decrease at edges. In landscapes with higher road density, the probability that forest edges are closer to roads increases, leading to a behavioural adjustment to road impacts. Furthermore, landscapes with higher road density make the overall matrix less permeable to bat movements, leading to more time spent in forest patches, as refuges, than in the matrix (Carr et al., 2002; Fahrig, 2003). In contrast, the activity of $N$. noctula at forest edges increased with road density, while it tended to decrease in interiors. As a highflying and open-space species, $N$. noctula may benefit from less heterospecific competition with other insectivorous bat species more sensitive to urban land cover effects such as the 'road-effect zone' (Claireau et al., 2019; Medinas et al., 2019). 


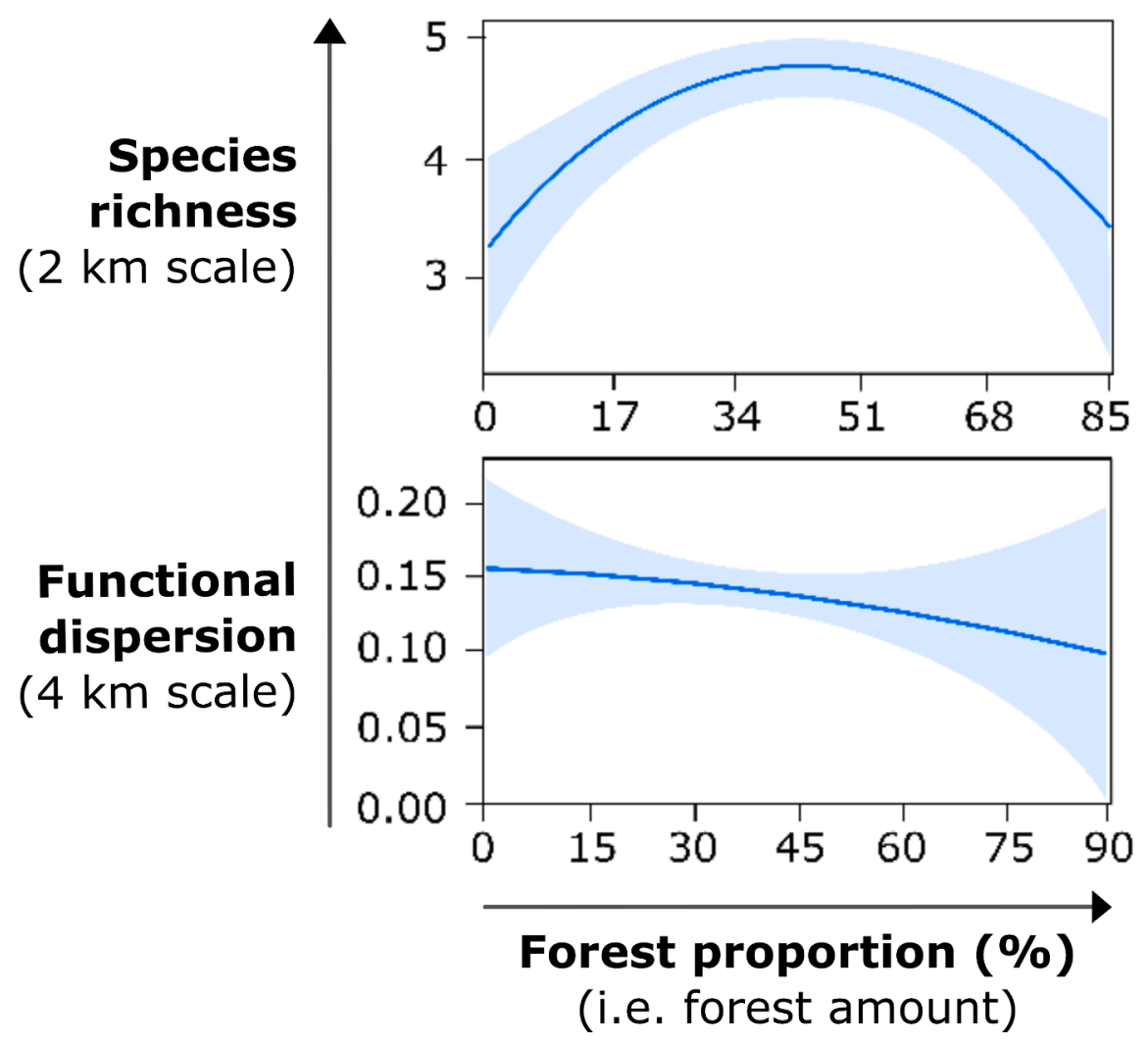

\section{Functional dispersion (4 km scale)}

\section{Phylogenetic diversity} (3 km scale)
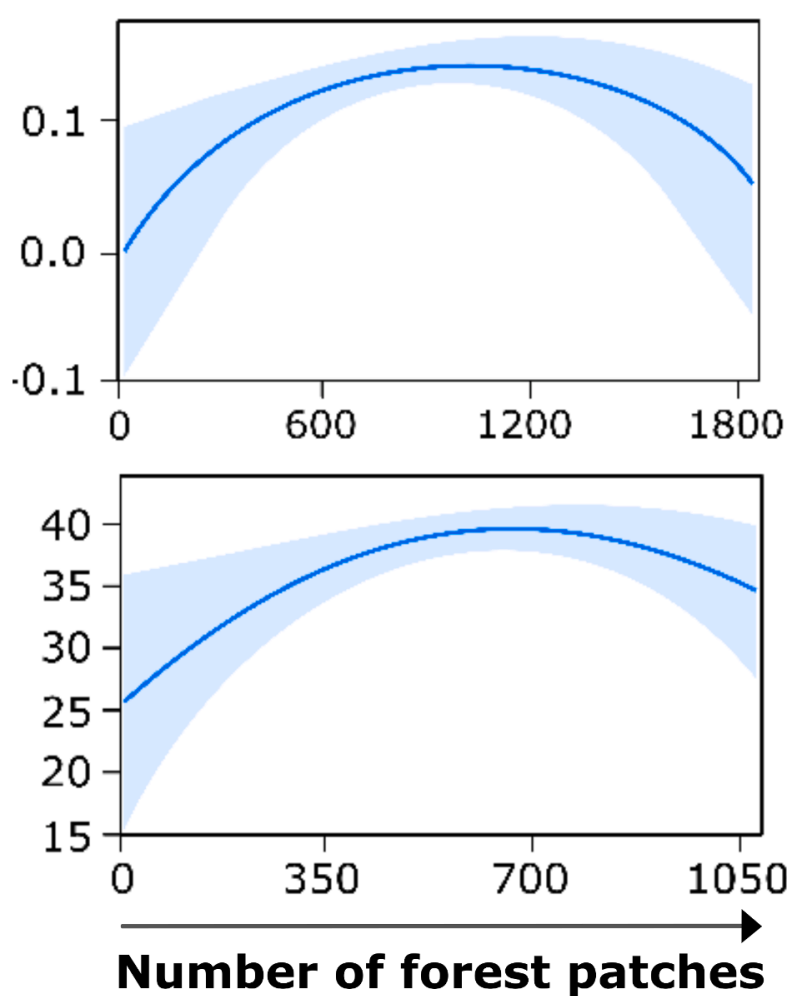

(i.e. forest patchiness)

Fig. 6. Variation in the three dimensions of bat diversity predicted (with the $95 \%$ confidence interval) in response to forest amount and patchiness at the 'scale of effect'. Only selected relationships in the best models are presented (i.e. RVI > 0.6; see Fig. 2). 


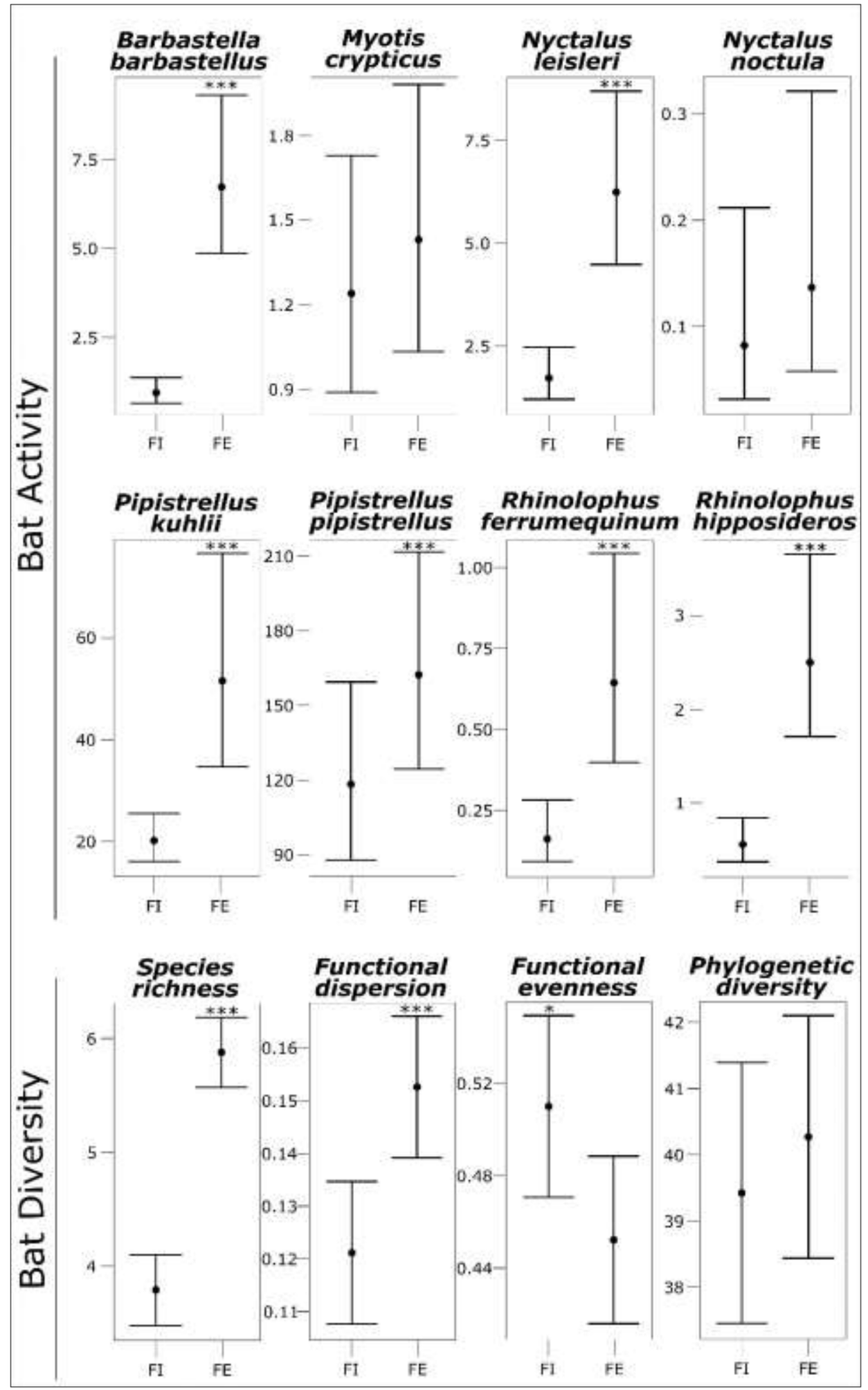

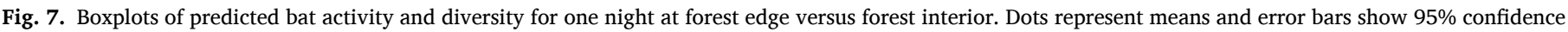
intervals. FI $=$ Forest Interior and $\mathrm{FE}=$ Forest Edge. Forest interior were used as the reference (i.e. intercept) in each model $(* * * P<0.001 ; * P<0.05)$.

Finally, as bat diversity and species activity did not consistently respond to vegetation structure (i.e. PCA axes) at both forest edge and interior, we suggest that the way bats use forest interiors and their edges for a given patch is mediated by local understorey complexity.

\subsection{Road density effects depend on forest fragmentation levels}

For four out of the eight bat species studied, we found significant interactions between road density and forest amount/patchiness, indicating that landscape context can significantly mediate road density effects. The activity of the two horsehoe bat species decreased with 
increasing road density only in landscapes with relatively few forest patches, while it increased with road density in landscapes with more forest patches for $P$. pipistrellus. Similarly, road density negatively affected $N$. leisleri in landscapes with a low amount of forest ( $<8 \%$ ), but it tended to be positive in more forested landscapes ( $>27 \%$ ). First, light and noise effects from traffic are likely higher in open areas than in forest-dominated landscapes, potentially resulting in a wider 'road-effect zone' (Medinas et al., 2019). In our study, the probability of being close to a major road was highest in the least forested landscapes, so that lower negative effects of road density in the most forested landscapes could be caused by a dominance of minor roads, probably less impactful. Second, forest patches are increasingly used by bats as road density increases and matrix quality decreases (as previously discussed). Third, in accordance with Ethier \& Fahrig (2011), we found that bat activity mainly increased with number of forest patches and decreased with forest amount. Two non-exclusive mechanisms can explain these findings:

(i) landscape complementation of non-substitutable resources found by bat in different habitats, since bats tend to forage in a wide range of habitats while most often roosting outside their preferential foraging habitat, as they depend on the availability of potential roosting structures in the landscape (Ancillotto et al., 2014; Downs et al., 2016). The quality of foraging habitats surrounding roosts actually plays a decisive role in roost choice for insectivorous bats (Boughey et al., 2011). An increase in the number of forest patches, with constant forest amount, decreases the mean distance between foraging and/or roosting sites, and therefore facilitate the landscape complementation process (Ethier \& Fahrig, 2011).

(ii) an increase in the number of forest patches also results in increased edge density at the landscape level therefore improving overall landscape connectivity for most bats (Ethier \& Fahrig, 2011). Our results confirmed an intensive use of forest edges for foraging and commuting, acting probably as a navigational reference, a source of insect prey, a shelter from wind, and a protection from predators (Morris et al., 2010).

Considering all these reasons together, we can thus suggest that an increase of forest patchiness (and amount, depending on species environmental requirements) offsets (at least partially) the negative effects of roads on bat populations at landscape level, improving the persistence of many species within landscapes of dense road network. Finally, by including habitat fragmentation and matrix quality variables in our analyses, we found that bat response to forest fragmentation was fully consistent with previous studies, suggesting that the confounding effect of matrix quality and road density would not consistently lead to misleading conclusions on the impact of forest fragmentation on bats. For instance, the decreasing bat diversity with increasing forest amount could not be due to hidden road-kill effects since major roads, implying highest bat mortality risk, were located in the least forested landscapes in our study.

\section{Conclusions}

We conclude that the protection of forest patches within most heavily human-altered landscapes and those having highest road density is critical to bat conservation (Bailey et al., 2019). Landscapes with moderately fragmented forests seem to maintain the highest bat diversity, even in case of high road density, thus reducing the expected magnitude of the wide negative impacts of roads by providing sufficient bat refuges in the landscape. By finding, for the first time, significant interactions between forest fragmentation and road density, our study provides more adequate recommendations towards a landscape planning that will improve the resilience of bat communities to both road expansion and forest fragmentation. Conservation efforts should focus on promoting forest patches within the most opened and road-densified landscapes, with a particular attention to road sections closest to forest where the probability of bat road-kills is higher (Medinas et al., 2021), but where conservation measures to maintain landscape connectivity, such as underpasses, are the most efficient (Laforge et al., 2019). Further research would help to clarify the impact of these interactive effects on long-term bat population persistence and shifts in community composition. Future road expansion will likely alter long-term species interactions, generating a loss of future options in evolutionary history for bat communities. We advocate for more research contributing to an improved understanding of the complex interactions between habitat fragmentation and matrix quality in mosaic landscapes, and valuing more holistic approaches in fragmentation studies.

\section{Declaration of Competing Interest}

The authors declare that they have no known competing financial interests or personal relationships that could have appeared to influence the work reported in this paper.

\section{Acknowledgements}

We would like to thank the following for their assistance in collecting field data: Richard Auriol, Julien Blanco, Jean-Philippe Choisis, Rémi Duflot, Jerome Molina, Clémence Moreau, Nirina Ratsimba, Nicolas Salliou and Magali San-Cristobal. We are also grateful to Wilfried Heintz and Florent Blaise for their dataset and IT help with the automatic sound identification and statistical analysis. We thank Kevin Barré for statistical advices and the Reviewers for their constructive comments. We also thank the IN2P3 Computing Centre for providing the facilities to process and archive the recordings, in particular Didier Bas. Funding was provided by 'Direction régionale de l'environnement, de l'aménagement et $\mathrm{du}$ logement' of Occitanie region (DREAL) and the French National Research and Technology Agency (ANRT) (CIFRE grant number: 2016/ 1063).

\section{Appendix A. Supplementary data}

Supplementary data to this article can be found online at https://doi. org/10.1016/j.landurbplan.2022.104353.

\section{References}

Ancillotto, L., Cistrone, L., Mosconi, F., Jones, G., Boitani, L., \& Russo, D. (2014). The importance of non-forest landscapes for the conservation of forest bats: Lessons from barbastelles (Barbastella barbastellus). Biodiversity and Conservation, 24, 171-185.

Andrieu, E., Cabanettes, A., Alignier, A., Van Halder, I., Alard, D., Archaux, F.,

Ouin, A. (2018). Edge contrast does not modulate edge effect on plants and pollinators. Basic and Applied Ecology, 27, 83-95.

Arroyo-Rodríguez, V., Rojas, C., Saldaña-Vázquez, R. A., \& Stoner, K. E. (2016). Landscape composition is more important than landscape configuration for phyllostomid bat assemblages in a fragmented biodiversity hotspot. Biological Conservation, 198, 84-92.

Bailey, A. M., Ober, H. K., Reichert, B. E., \& McCleery, R. A. (2019). Canopy Cover Shapes Bat Diversity across an Urban and Agricultural Landscape Mosaic. Environmental Conservation, 46, 193-200.

Barré, K., Le Viol, I., Julliard, R., Pauwels, J., Newson, S. E., Julien, J., ... Bas, Y. (2019). Accounting for automated identification errors in acoustic surveys. Methods in Ecology and Evolution, 10(8), 1171-1188.

Bas, Y., Bas, D., \& Julien, J. (2017). Tadarida : A Toolbox for Animal Detection on Acoustic Recordings. Journal of Open Research Software, 5.

Bennett, V. J., \& Zurcher, A. A. (2013). When corridors collide: Road-related disturbance in commuting bats. Journal of Wildlife Management, 77, 93-101.

Bodin, J., Boléat, C., Déjean, S., Dubourg-Savage, M.-J., Gaches, L., Liozon, R., Milhas, C., Nemoz, M., Néri, F., Pavan, A., Prud'homme, F. \& Ventre, V. (2011) Les chauvessouris de Midi-Pyrénées: répartition, écologie, conservation (The bats of MidiPyrénées: distribution, ecology and conservation), (ed. by Conservatoire régional des espaces naturels de Midi-Pyrénées) and Groupe Chiroptère de Midi-Pyrénées) Conservatoire régional des espaces naturels de Midi-Pyrénées, Toulouse.

Boughey, K. L., Lake, I. R., Haysom, K. A., \& Dolman, P. M. (2011). Effects of landscapescale broadleaved woodland configuration and extent on roost location for six bat species across the UK. Biological Conservation, 144, 2300-2310.

Burnham, K. P., \& Anderson, D. R. (2002). Model Selection and Multimodel Inference: A Practical Information-Theoretic Approach (2nd ed.). New York: Springer.

Carr, L.W., Fahrig, L. \& Pope, S.E. (2002) Impacts of landscape transformation by roads. Applying landscape ecology in biological conservation (ed. by Springer), pp. 225-243. New York. 
Cisneros, L. M., Burgio, K. R., Dreiss, L. M., Klingbeil, B. T., Patterson, B. D., Presley, S. J., \& Willig, M. R. (2014). Multiple dimensions of bat biodiversity along an extensive tropical elevational gradient. Journal of Animal Ecology, 83, 1124-1136.

Cisneros, L. M., Fagan, M. E., \& Willig, M. R. (2015). Effects of human-modified landscapes on taxonomic, functional and phylogenetic dimensions of bat biodiversity. Diversity and Distributions, 21, 523-533.

Claireau, F., Bas, Y., Pauwels, J., Barré, K., Machon, N., Allegrini, B., ... Kerbiriou, C. (2019). Major roads have important negative effects on insectivorous bat activity. Biological Conservation, 235, 53-62.

Dencker, T. S., Pecuchet, L., Beukhof, E., Richardson, K., Payne, M. R., \& Lindegren, M. (2017). Temporal and spatial differences between taxonomic and trait biodiversity in a large marine ecosystem: Causes and consequences. PLOS ONE, 12, Article e0189731.

Devictor, V., Mouillot, D., Meynard, C., Jiguet, F., Thuiller, W., \& Mouquet, N. (2010). Spatial mismatch and congruence between taxonomic, phylogenetic and functional diversity: The need for integrative conservation strategies in a changing world. Ecology Letters, 13, 1030-1040.

Downs, N. C., Cresswell, W. J., Reason, P., Sutton, G., Wells, D., \& Wray, S. (2016). SexSpecific Habitat Preferences of Foraging and Commuting Lesser Horseshoe Bats Rhinolophus hipposideros (Borkhausen, 1797) in Lowland England. Acta Chiropterologica, 18, 451-465.

Ducci, L., Agnelli, P., Di Febbraro, M., Frate, L., Russo, D., Loy, A., ... Roscioni, F. (2015). Different bat guilds perceive their habitat in different ways: A multiscale landscape approach for variable selection in species distribution modelling. Landscape ecology, 30(10), 2147-2159.

Ethier, K., \& Fahrig, L. (2011). Positive effects of forest fragmentation, independent of forest amount, on bat abundance in eastern Ontario, Canada. Landscape Ecology, 26, 865-876.

Fahrig, L. (2003). Effects of habitat fragmentation on biodiversity. Annual Review of Ecology, Evolution, and Systematics, 34, 487-515.

Fahrig, L., \& Rytwinski, T. (2009). Effects of roads on animal abundance: An empirical review and synthesis. Ecology and society, 14(1).

Fahrig, L. (2017). Ecological Responses to Habitat Fragmentation Per Se. Annual Review of Ecology, Evolution, and Systematics, 48, 1-23.

Fahrig, L. (2019). Habitat fragmentation: A long and tangled tale. Global Ecology and Biogeography, 28(1), 33-41.

Faith, D. P. (1992). Conservation evaluation and phylogenetic diversity. Biological Conservation, 61, 1-10.

Fensome, A. G., \& Mathews, F. (2016). Roads and bats: A meta-analysis and review of the evidence on vehicle collisions and barrier effects. Mammal Review, 46, 311-323.

Fuentes-Montemayor, E., Goulson, D., \& Park, K. J. (2011). Pipistrelle bats and their prey do not benefit from four widely applied agri-environment management prescriptions. Biological Conservation, 144(9), 2233-2246.

Fuentes-Montemayor, E., Goulson, D., Cavin, L., Wallace, J. M., \& Park, K. J. (2013). Fragmented woodlands in agricultural landscapes: The influence of woodland character and landscape context on bats and their insect prey. Agriculture, Ecosystems and Environment, 172, 6-15.

Fuentes-Montemayor, E., Watts, K., Macgregor, N. A., Lopez-Gallego, Z., \& Park, K. (2017). Species mobility and landscape context determine the importance of local and landscape-level attributes. Ecological Applications, 38, 42-49.

Gorresen, P. M., \& Willig, M. R. (2004). Landscape responses of bats to habitat fragmentation in Atlantic forest of Paraguay. Journal of Mammalogy, 85, 688-697.

Inglada, J., Vincent, A., Arias, M., Tardy, B., Morin, D., \& Rodes, I. (2017). Operationa High Resolution Land Cover Map Production at the Country Scale Using Satellite Image Time Series. Remote Sensing, 9(1), 95.

Jackson, H. B., \& Fahrig, L. (2012). What size is a biologically relevant landscape? Landscape Ecology, 27, 929-941.

Jackson, H. B., \& Fahrig, L. (2015). Are ecologists conducting research the optimal scale? Global Ecology and Biogeography, 24, 52-63.

Juste, J., Ruedi, M., Puechmaille, S. J., Salicini, I., \& Ibáñez, C. (2018). Two New Cryptic Bat Species within the Myotis nattereri Species Complex (Vespertilionidae, Chiroptera) from the Western Palaearctic. Acta Chiropterologica, 20, 285-300.

Khamcha, D., Corlett, R. T., Powell, L. A., Savini, T., Lynam, A. J., \& Gale, G. A. (2018) Road induced edge effects on a forest bird community in tropical Asia. Avian Research, 9, 1-13.

Klingbeil, B. T., \& Willig, M. R. (2009). Guild-specific responses of bats to landscape composition and configuration in fragmented Amazonian rainforest. Journal of Applied Ecology, 46, 203-213.

Laforge, A., Archaux, F., Bas, Y., Gouix, N., Calatayud, F., Latge, T., \& Barbaro, L. (2019). Landscape context matters for attractiveness and effective use of road underpasses by bats. Biological Conservation, 237, 409-422.

Laliberté, E., \& Legendre, P. (2010). A distance-based framework for measuring functional diversity from multiple traits. Ecology, 91, 299-305.

Langridge, J., Pisanu, B., Laguet, S., Archaux, F., \& Tillon, L. (2019). The role of complex vegetation structures in determining hawking bat activity in temperate forests. Forest Ecology and Management, 448, 559-571.
Laurance, W. F., Clements, G. R., Sloan, S., O’Connell, C. S., Mueller, N. D., Goosem, M., Arrea, I. B. (2014). A global strategy for road building. Nature, 513, 229-232.

McCain, C. M. (2006). Could temperature and water availability drive elevational species richness patterns? A global case study for bats. Global Ecology and Biogeography, 16 (1), 1-13.

Medinas, D., Marques, J. T., Costa, P., Santos, S., Rebelo, H., Barbosa, A. M., \& Mira, A. (2021). Spatiotemporal persistence of bat roadkill hotspots in response to dynamics of habitat suitability and activity patterns. Journal of Environmental Management, 277, Article 111412.

Medinas, D., Ribeiro, V., Marques, J. T., Silva, B., Barbosa, A. M., Rebelo, H., \& Mira, A. (2019). Road effects on bat activity depend on surrounding habitat type. Science of the Total Environment, 660, 340-347.

Miguet, P., Jackson, H. B., Jackson, N. D., Martin, A. E., \& Fahrig, L. (2016). What determines the spatial extent of landscape effects on species? Landscape Ecology, 31 (6), 1177-1194.

Millon, L., Julien, J. F., Julliard, R., \& Kerbiriou, C. (2015). Bat activity in intensively farmed landscapes with wind turbines and offset measures. Ecological Engineering, 75, 250-257.

Monnet, A. C., Jiguet, F., Meynard, C. N., Mouillot, D., Mouquet, N., Thuiller, W., \& Devictor, V. (2014). Asynchrony of taxonomic, functional and phylogenetic diversity in birds. Global Ecology and Biogeography, 23, 780-788.

Morris, A. D., Miller, D. A., \& Kalcounis-Rueppell, M. C. (2010). Use of Forest Edges by Bats in a Managed Pine Forest Landscape. Journal of Wildlife Management, 74, 26-34.

Norberg, U. M., \& Rayner, J. M. V. (1987). Ecological Morphology and Flight in Bats (Mammalia; Chiroptera): Wing Adaptations, Flight Performance, Foraging Strategy and Echolocation. Philosophical Transactions of the Royal Society B: Biological Sciences, $316,335-427$.

Obrist, M. K., Boesch, R., \& Fluckiger, P. F. (2004). Variability in echolocation call design of 26 Swiss bat species: Consequences, limits and options for automated field identification with a synergetic pattern recognition approach. Mammalia, 68, 307-322.

Petchey, O. L., \& Gaston, K. J. (2006). Functional diversity: Back to basics and looking forward. Ecology Letters, 9, 741-758.

Pfeifer, M., Lefebvre, V., Peres, C. A., Banks-Leite, C., Wearn, O. R., Marsh, C. J., et al. (2017). Creation of forest edges has a global impact on forest vertebrates. Nature, 551(7679), 187-191.

Presley, S. J., Cisneros, L. M., Klingbeil, B. T., \& Willig, M. R. (2019). Landscape ecology of mammals. Journal of Mammalogy, 100, 1044-1068.

R Core Team (2018) R: A language and environment for statistical computing.

Roemer, C., Coulon, A., Disca, T., \& Bas, Y. (2019). Bat sonar and wing morphology predict species vertical niche. The Journal of the Acoustical Society of America, 145(5), 3242-3251.

Russo, D., \& Ancillotto, L. (2015). Sensitivity of bats to urbanization: A review. Mammalian Biology - Zeitschrift für Säugetierkunde, 80, 205-212.

Santos, S. M., Mira, A., Salgueiro, P. A., Costa, P., Medinas, D., \& Beja, P. (2016). Avian trait-mediated vulnerability to road traffic collisions. Biological Conservation, 200, $122-130$.

Schielzeth, H. (2010). Simple means to improve the interpretability of regression coefficients. Methods in Ecology and Evolution, 1(2), 103-113.

Smith, A. C., Koper, N., Francis, C. M., \& Fahrig, L. (2009). Confronting collinearity: Comparing methods for disentangling the effects of habitat loss and fragmentation. Landscape Ecology, 24, 1271-1285.

Stone, E. L., Harris, S., \& Jones, G. (2015). Impacts of artificial lighting on bats: A review of challenges and solutions. Mammalian Biology - Zeitschrift für Säugetierkunde, 80, 213-219.

Tucker, M. A., Böhning-Gaese, K., Fagan, W. F., Fryxell, J. M., Van Moorter, B., Alberts, S. C., ... Mueller, T. (2018). Moving in the Anthropocene: Global reductions in terrestrial mammalian movements. Science, 359(6374), 466-469.

Vamosi, S. M., Heard, S. B., Vamosi, J. C., \& Webb, C. O. (2009). Emerging patterns in the comparative analysis of phylogenetic community structure. Molecular Ecology, 18, 572-592.

Villéger, S., Mason, N. W. H., \& Mouillot, D. (2008). New multidimensional functiona diversity indices for a multifaceted framework in functional ecology. Ecology, 89, 2290-2301.

Zimmermann Teixeira, F., Kindel, A., Hartz, S. M., Mitchell, S., \& Fahrig, L. (2017). When road-kill hotspots do not indicate the best sites for road-kill mitigation. Journal of Applied Ecology, 54(5), 1544-1551.

Zuckerberg, B., Cohen, J. M., Nunes, L. A., et al. (2020). A Review of Overlapping Landscapes: Pseudoreplication or a Red Herring in Landscape Ecology? Current Landscape Ecology Reports, 5, 140-148.

Zuur, A. F., Ieno, E. N., Walker, N. J., Saveliev, A. A., \& Smith, G. M. (2009). Mixed effects models and extensions in ecology with $R$. New York, NY: Spring Science and Business Media. 